\title{
DROSERA SLACKII CHEEK
}

Nigel Hewitt-Cooper • The Homestead • Glastonbury Road • West Pennard • Somerset, BA6 8NN • UK・sales@hccarnivorousplants.co.uk

Keywords: Cultivation: Drosera slackii.

South Africa is renowned among carnivorous plant growers for its Drosera, with stunning species such as D. cistiflora and D. pauciflora, and also a number of rosetted species. For some, these species hold little appeal, but as with many plants I feel a closer look is required to appreciate the finer beauty of these plants. Drosera slackii, named after Adrian Slack, was discovered as recently as 1979, and named in 1987, being placed in section Drosera within the genus. It ranks as one of the most impressive rosetted Drosera, and can be confused with no other (Fig. 1).

Found around the Cape region of South Africa, the deep red rosettes can reach $7.5 \mathrm{~cm}$ in diameter, with narrowly cuneate leaves with a distinct bulge on the petiole (Fig. 1). There is a conspicuous bright red multi lobed stipule at each leaf base, and the rear of the leaf has a number of coarse red hairs, predominately on the petiole section, with a few extending on to the rear of the lamina.

The upper surface of the lamina is covered in the characteristic insect catching glandular tentacles, with a single line of non-sticky, longer hairs to $8 \mathrm{~mm}$ in length along the apex. Each of these is topped with a cylindrical, non-sticky gland, the purpose of which is to hold in place a large struggling insect whilst the sticky glandular hairs gradually curl over and make contact. These so-called "snap tentacles" are found in number of rosetted species, and are capable of extremely rapid movement, often bending through $180^{\circ}$ in as little as half a second. Like all rosetted Drosera, the leaves themselves are able to roll over completely to ensure as many hairs as possible are in contact with the insect prey.

After a few years, D. slackii becomes pedestal forming, with the live rosette sitting on top of a column of previous year's dead growth, in the same way as the well known $D$. roraimae of Venezuela (Fig. 2). I have a few plants which have remained in the same pot for 6 years and are now approximately $7.5 \mathrm{~cm}$ high. To produce this effect it seems important to regularly flush through the compost from above with rain water. I have found that after 3-4 years of being in the same compost, the rosettes of many species start to lack vigour and reduce in size. This I believe is due to a build up of minerals in the upper layer of the compost, brought about by the constant upward imbibement of water. No matter how pure the water used, there will always be an element, however small, of mineral salts which will accumulate in the upper surface, and must be detrimental to growth. For the past 4 years I have regularly flushed the Drosera plants from above, usually every 3-4 weeks in the
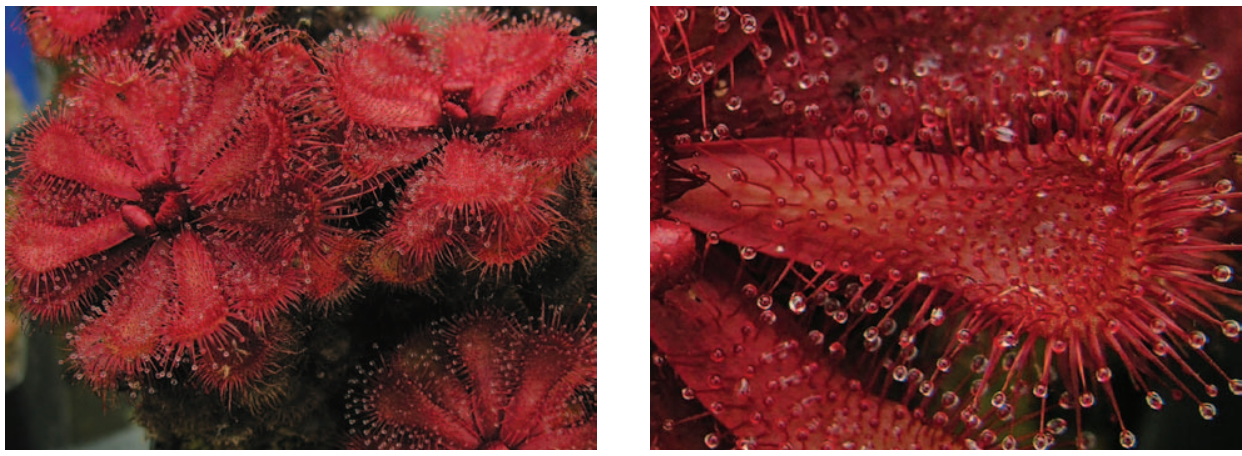

Figure 1: Deep crimson rosettes of Drosera slackii (left) and closeup of lamina (right). 


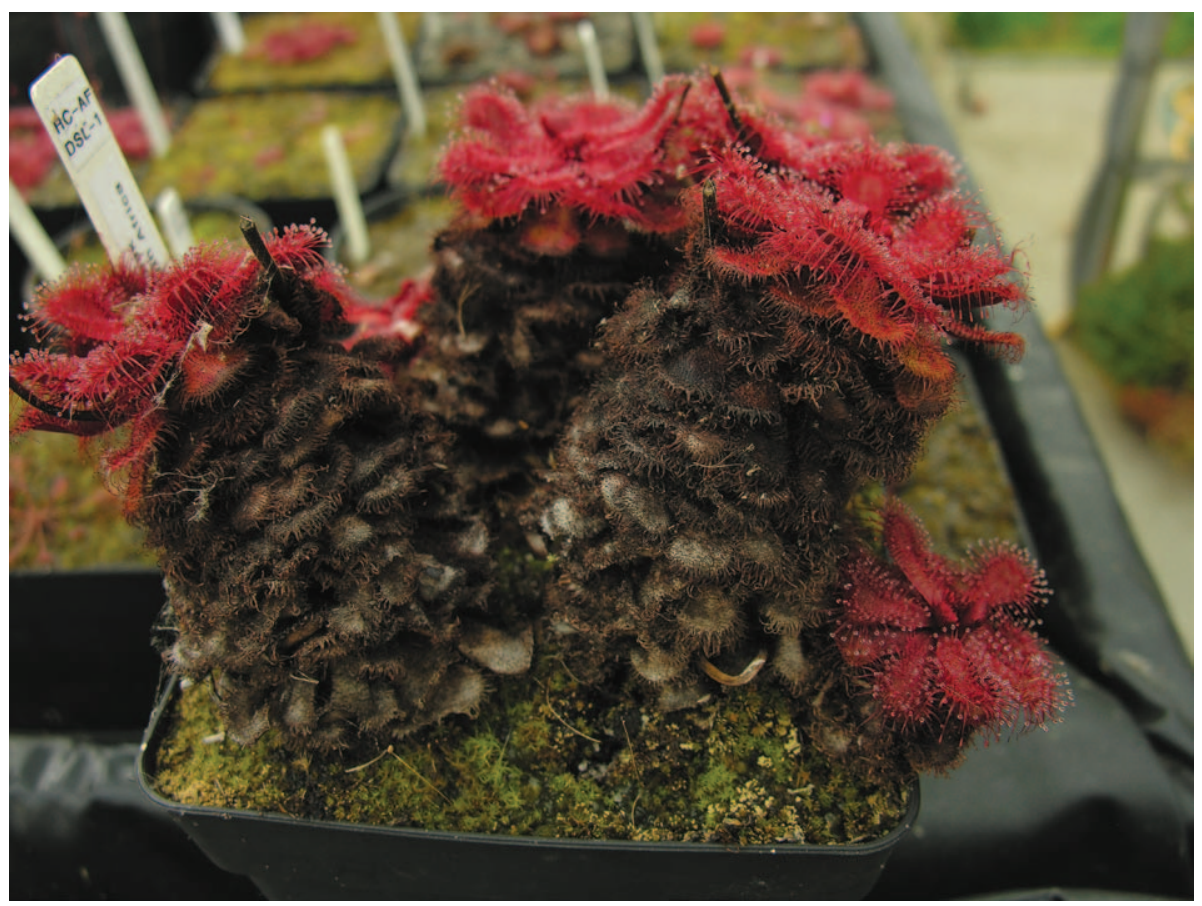

Figure 2: Old pedestal forming rosettes.

growing season, with the result that the plants have thrived, with none of the reduction in rosette size previously seen. In the wild of course, the natural rainfall will have the same effect.

It would be interesting for this theory to be tested-a task I shall leave to someone somewhat more technically minded than myself.

A few years ago, I discovered another interesting phenomenon with this species. A hundred or so plants were on a bench in the nursery, and as I passed them I bent down to retrieve something off of the floor. As I stooped down past the level of the plants, I was struck by a strong floral perfume, which on closer investigation was being produced by the rosettes themselves, rather than the flowers
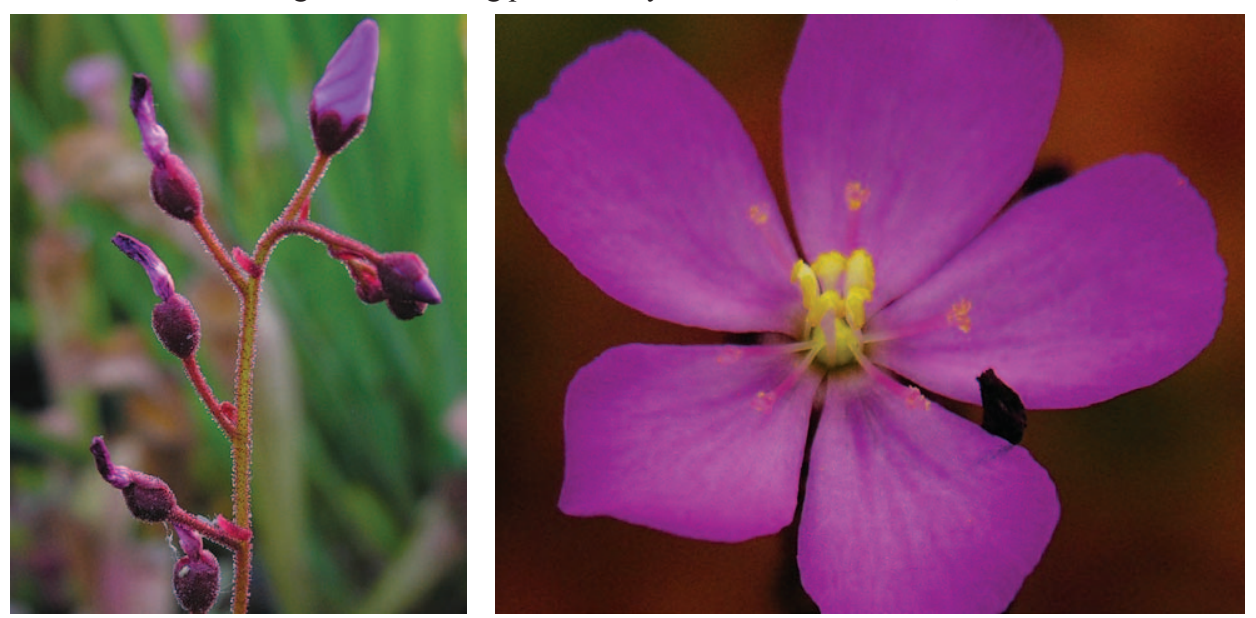

Figure 3: Glandular scape (left) and closeup of flower (right). 

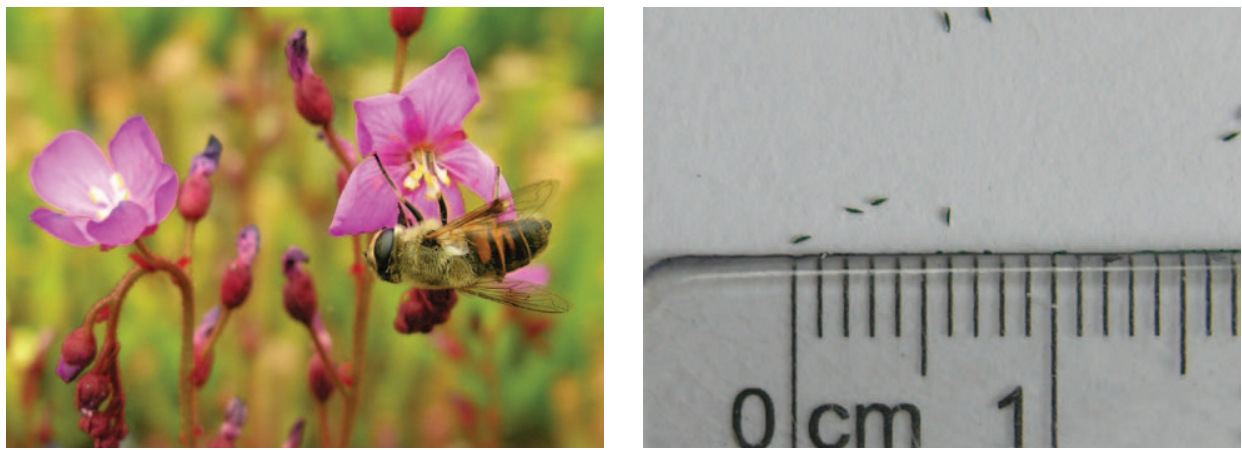

Figure 4: Hover fly pollinating the flowers (left) and tiny fusiform Drosera slackii seeds (right). which have no fragrance. One can only assume that this acts as an attractant for insect prey, but I have found no reference to it elsewhere.

In early summer, tall wiry glandular stems (Fig. 3) to approximately $50 \mathrm{~cm}$ are produced with 20 25 bright purple-pink flowers to $1.25 \mathrm{~cm}$ in diameter, each with 6 bifid stigma tips, and each opening for a single day (Fig. 3). I have seen the flowers pollinated by hover flies in the nursery (Fig. 4).

Seed set on this species seems to be poor, with comparatively few produced when compared to other South African plants. The seeds are fusiform, blunt at one end, and $0.75 \mathrm{~mm}$ in length (Fig. 4).

I keep my plants in full sun, in a compost of silver sand and moss peat to a ratio of 2:1, and standing in $2-5 \mathrm{~cm}$ of rain water in the summer months, reducing down to keep just damp over the winter with a minimum temperature of $7^{\circ} \mathrm{C}$. At these temperatures the plants remain in growth all year, though the rate of growth decreases considerably over the winter.

I have subjected this species to sub-zero temperatures, down to as low as $-6^{\circ} \mathrm{C}$, the result of which was the destruction of the rosettes, but re-growth from the long wiry roots occurred the following spring with new shoots emerging in April.

Individual plants will, in time, divide and can produce a dense colony. These can be divided and potted separately. Root cuttings work well, and in early spring adult plants can simply be removed from their pots, the lower $50 \%$ of the roots removed, and these laid out on the surface of some compost and lightly covered with the same. Re-pot the adult plants. Keep the compost with cuttings standing in rain water and in full sun, and tiny rosettes will begin to develop within 6 weeks.

Seed also works, and can simply be surface sown in the spring and treated as the root cuttings above. Germination occurs in 2-4 weeks.

This species is available from www.hccarnivorousplants.co.uk

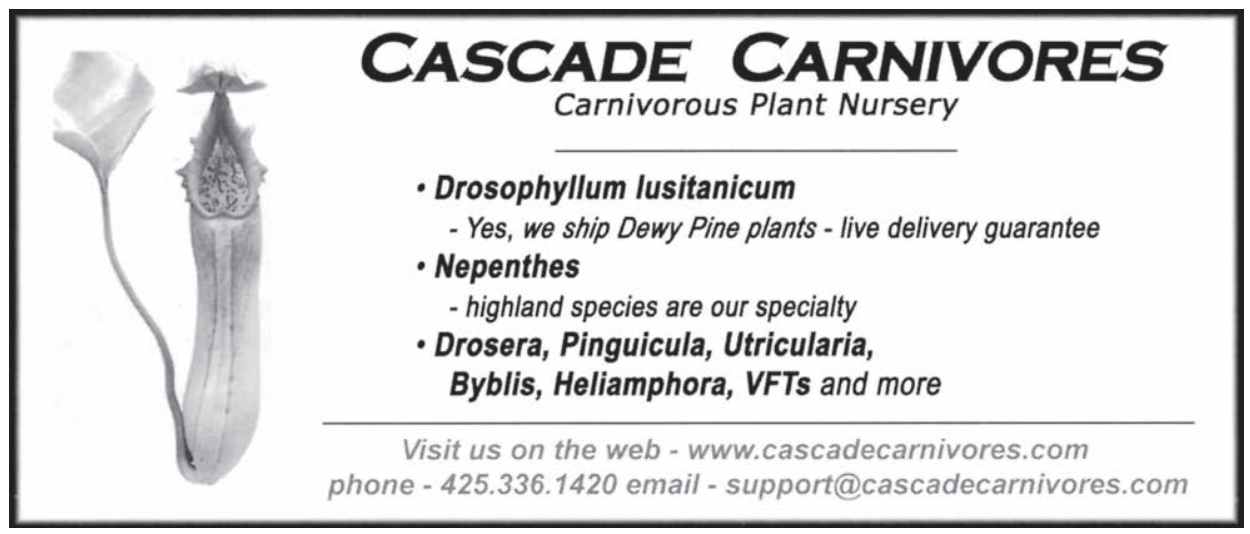

